\title{
Digital Learning Network Education Events for the Desert Research and Technology Studies
}

\author{
Heather L. Paul \\ NASA Johnson Space Center \\ Erika R. Guillory \\ NASA Johnson Space Center - JIMMS Contract
}

Copyright @ 2007 SAE International

\begin{abstract}
NASA's Digital Learning Network (DLN) reaches out to thousands of students each year through video conferencing and webcasting. As part of NASA's Strategic Plan to reach the next generation of space explorers, the DLN develops and delivers educational programs that reinforce principles in the areas of science, technology, engineering and mathematics. The DLN has created a series of live education videoconferences connecting the Desert Research and Technology Studies (RATS) field test to students across the United States. The programs are also extended to students around the world via live webcasting. The primary focus of the events is the Vision for Space Exploration. During the programs, Desert RATS engineers and scientists inform and inspire students about the importance of exploration and share the importance of the field test as it correlates with plans to return to the Moon and explore Mars. This paper describes the events that took place in September 2006.
\end{abstract}

\section{INTRODUCTION}

NASA's Digital Learning Network is the agency's educational video teleconferencing team that delivers NASA content to classrooms across the United States and around the world. The network includes all NASA education offices associated with its ten field centers and NASA Headquarters.

The goal of NASA's Digital Learning Network is to enhance NASA's capability to deliver unique content by linking customers with one or more NASA centers across the country. The distance learning initiative provides a unique experience for students and educators at kindergarten through twelfth grade and university levels, bringing unique content, facilities and personnel directly into their classrooms. Students at all levels have the opportunity to interact directly with NASA scientists and educational specialists to gain a new appreciation for the importance of science and education.

\section{DESERT RATS EDUCATION EVENTS}

\section{MAIN OBJECTIVES}

For two weeks each September, NASA scientists and engineers travel to Arizona to conduct the Desert RATS field evaluations. During the tests, planetary surface exploration activities are simulated so that participants can test out the designs for extravehicular activity (EVA) exploration systems. These evaluations help NASA develop well-defined requirements to support the vision for space exploration initiative. Evaluations often include interactions between space suited test subjects and robotic and communications systems.

The Digital Learning Network's primary goal is to inspire the next generation of space explorers. Through video conferencing technology, network sites disseminate NASA educational content to students and educators across the United States. The DLN partnership with the Desert Research and Technologies Studies group has given students an opportunity to see NASA scientists and engineers at work in the field. The live, interactive events offer students a first hand look at testing of future concepts for space suits and robots that may be a part of future missions to the Moon and Mars. Students are given an opportunity to ask questions and interact with the host and subject matter experts during the program. This direct link to the project reinforces the importance of science, technology, engineering, math and geography in the plans for future exploration. Figure 1 shows the students interacting with the DLN host and other schools that are also participating in the program. 


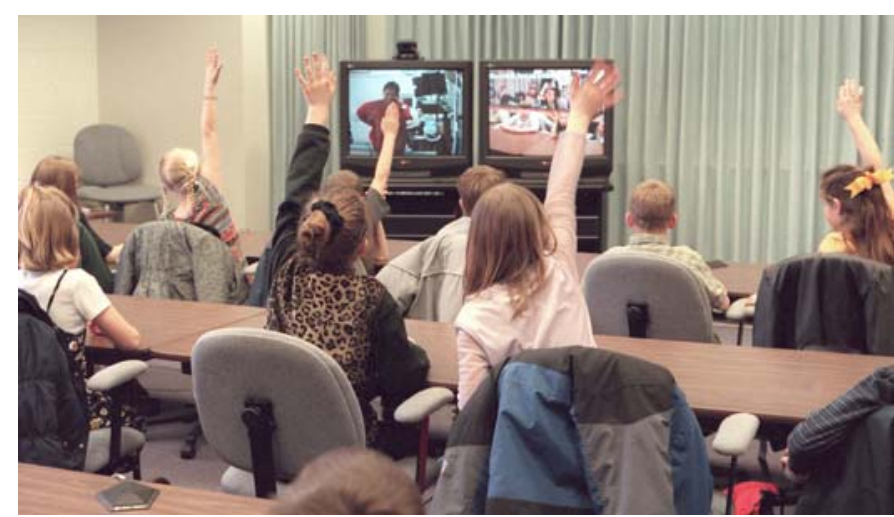

Figure 1. Classroom view of students interacting with DLN Host

\section{PREVIOUS DESERT RATS DLN EVENTS}

The Desert RATS collaboration with DLN began in 2004 . The four events targeted students in grades five through twelve, and covered topics including why testing is being done in the Arizona desert, communications, a space suit overview and discussion with the suited test subject, and an overview of what additional equipment is being evaluated in the field. In preparation for the events, teachers and students were encouraged to access online activities and information about Desert RATS. During the events, students had the opportunity to converse with the NASA scientists and engineers and ask questions (live and via email) about the technology and equipment. Post-event activities were also available on-line to complete the learning experience.

The Desert RATS DLN events were again conducted in 2005. The number of events was increased to six, in which three were webcasts and the other three were direct linked to specific schools. Similar to the 2004 events, the target audience was students in grades five through twelve. Activities were available online to allow students to prepare for the events prior to the programming, and to conduct post-event activities to solidify the lessons learned during the education events. The live programs included a host and subject matter experts from Glenn Research Center and Johnson Space Center (JSC) to discuss the topics of communications, sample collection, space suits and rovers and robots. Figures 2 and 3 show the setup of the DLN equipment, the host and subject matter expert interaction, and the rovers and space suit donning stand backgrounds that were available during the programs.

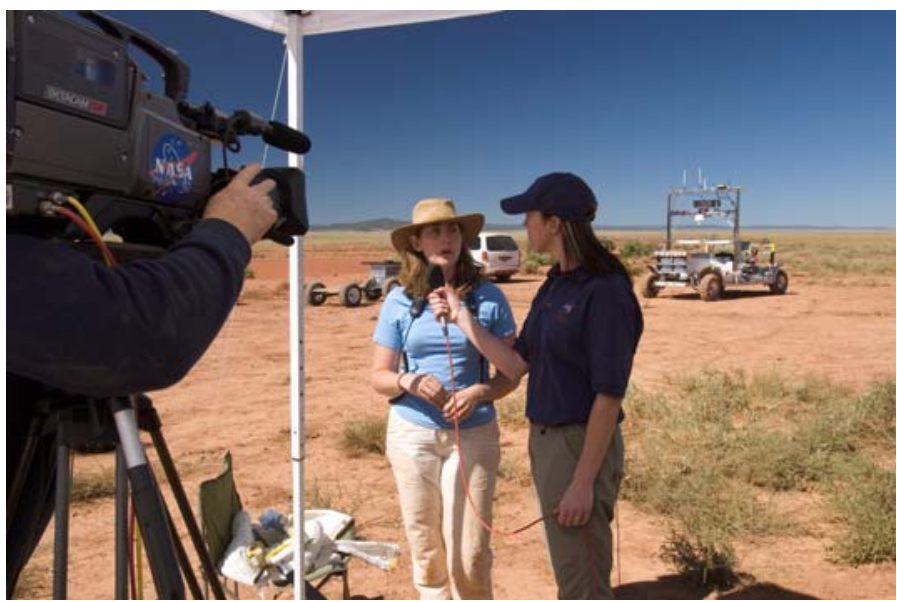

Figure 2. 2005 Desert RATS DLN event - Host Heather Paul and Dr. Jennifer Rochlis (SCOUT in the background)

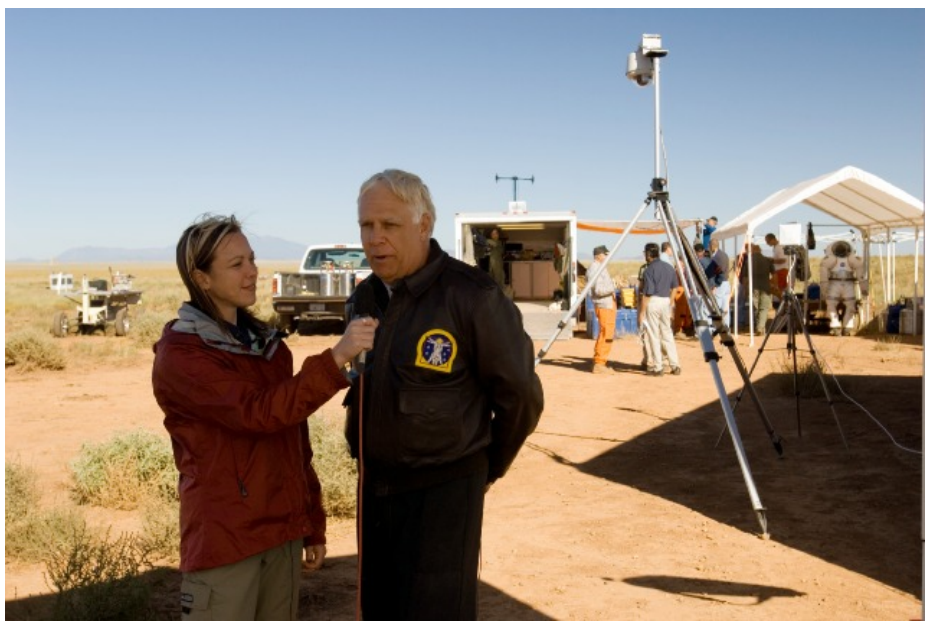

Figure 3. 2005 Desert RATS DLN event - Host Heather Paul and Space Suit Test Subject Dean Eppler (Space Suit Donning Stand in the background)

\section{DESERT RATS DLN EVENT DETAILS}

In 2006, the collaboration between the DLN and Desert RATS teams continued with six education programs. Similar to the 2005 programs, three events were webcasts, and the other three were direct linked to specific schools. Two programs were conducted each day on September 12, 13, and 14. The focus of Desert RATS in 2006 was human-robotic interaction, and therefore the technical content of the education events featured discussions on the Science Crew Operations and Utility Testbed (SCOUT) and the All-Terrain HexLegged Extra-Terrestrial Explorer (ATHLETE), as well as the two space suits that were being evaluated, the Mark III and I-suit. Figure 4 shows the DLN crew, host and space suit subject matter experts preparing for the segment on space suits. 


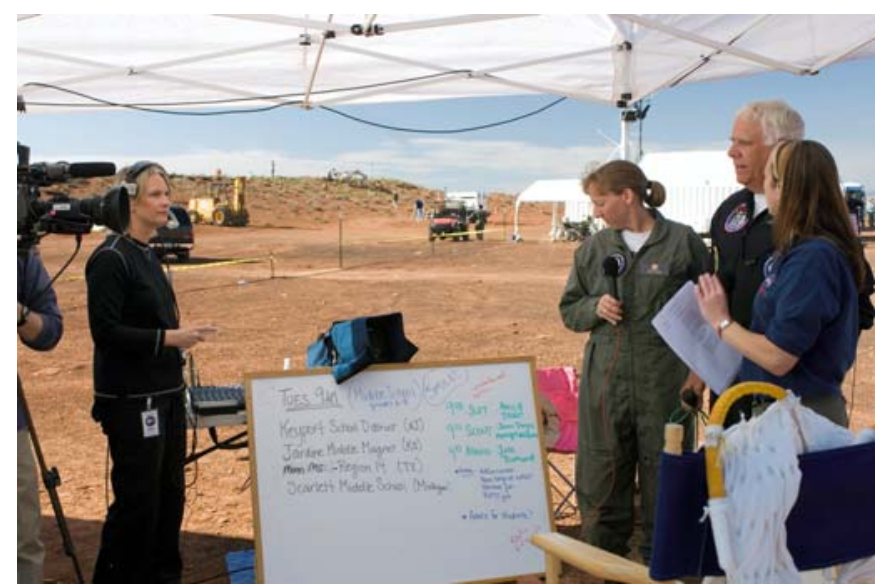

Figure 4. 2006 Desert RATS DLN event - DLN crew prepares to interview Desert RATS participants Amy Ross and Dean Eppler

The 2006 events included more interaction between the DLN Studio at JSC, and the field crew in Arizona. In between segments between the host and subject matter experts in the field, the JSC DLN studio conducted further discussions on the technical topics, and showed Brain Bites clips. This break in the programming from the field added more diversity of information to the programming and gave the field crew time to set up for their next segment. It also created even more interaction with the students, as student questions could be addressed during both the studio and field segments. Figures 5 and 6 show the studio setup.

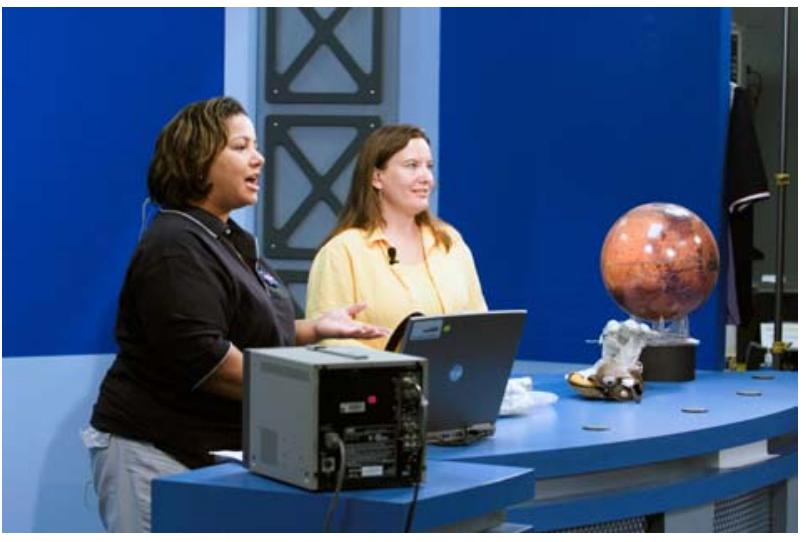

Figure 5. DLN Host Erika Guillory shares commentary with NASA Engineer Gretchen Thomas

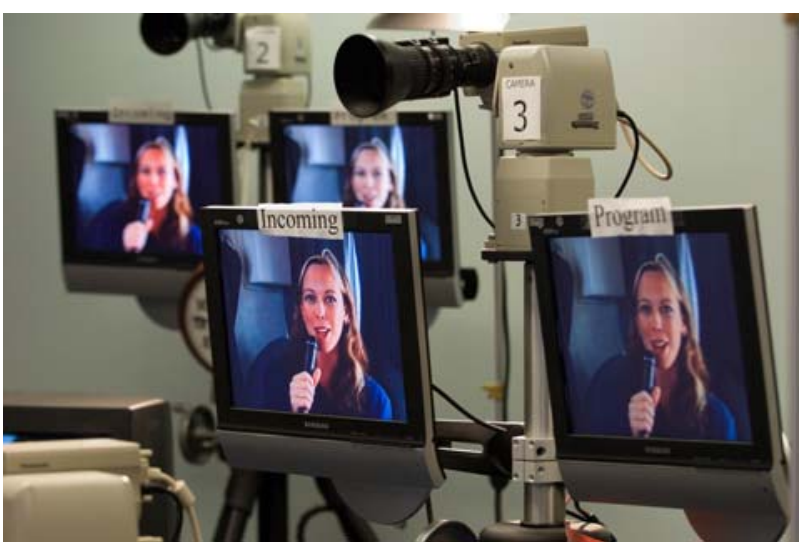

Figure 6. DLN Field Reporter Heather Paul "live" from Desert RATS field site on studio cameras

\section{TARGET AUDIENCE}

The Digital Learning Network's target audience consists of students in grades kindergarten through twelve attending schools in the United States. The network strives to reach targeted populations associated with the NASA Explorer Schools Program and other NASA distance learning initiatives that target underserved populations while providing access to members of the general education community that have videoconferencing and/or webcasting capability.

During the 2006 Desert RATS DLN programming, 1283 students participated in the events. The majority of students that participated were in grades five through eight, as shown in Figure 1. Students in grades nine through twelve, and one university class also participated in the events. Table 1 shows the distribution of schools and grade levels that participated in the programs.

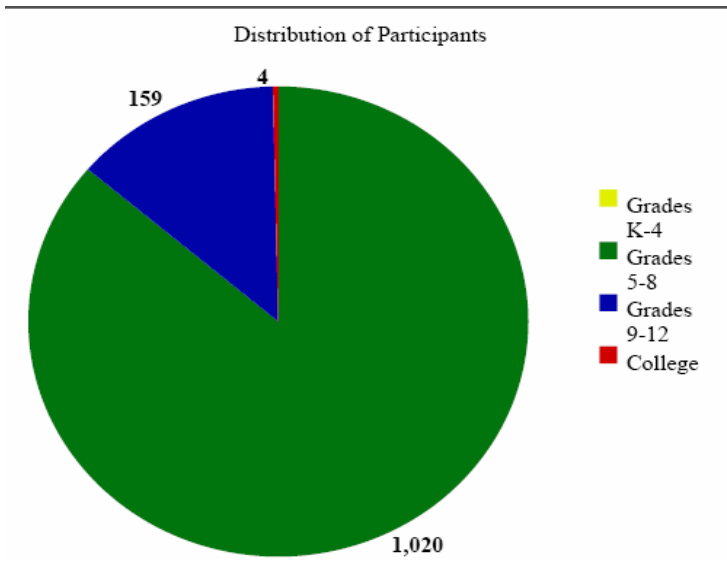

Figure 1. Desert RATS Participants by Grade Distribution 


\begin{tabular}{|c|c|c|}
\hline State & $\begin{array}{c}\text { Number of } \\
\text { Schools }\end{array}$ & Grades \\
\hline Connecticut & 1 & $5-8$ \\
\hline Georgia & 1 & $6-8$ \\
\hline lowa & 1 & 7 \\
\hline Kansas & 1 & $6-8$ \\
\hline Louisiana & 1 & $9-12$ \\
\hline Massachusett & 1 & $6-8$ \\
\hline s & 1 & $6-8$ \\
\hline Mew Jersey & 2 & $6-8$ \\
\hline New York & 2 & $5-8$ \\
\hline Ohio & 1 & Universit \\
\hline South Carolina & 1 & y \\
\hline Texas & 7 & $6-12$ \\
\hline Virginia & 2 & $5-12$ \\
\hline
\end{tabular}

Table 1. Desert RATS Participants by State and Grade Level

\section{PROJECT FEEDBACK}

Feedback from the Desert RATS subject matter experts and technical team, as well as the students and educators, helps the DLN team determine how to improve the Desert RATS programs from year to year. Overall the feedback has been extremely positive, indicating that these events are educational and enjoyable, and worth continuing in future Desert RATS field events.

"The Desert RATS DLN programs are important to increase student awareness of NASA's vision for space exploration. They learn about what Desert RATS is, why it is important, what hardware is tested, and how Desert RATS will help us get to the Moon and onto Mars. They get excited about what we're doing, and they learn that they can get there themselves by studying hard and doing well in school. They really are the next generation of explorers who will extend human presence across the solar system and beyond."

Barbara Janoiko

Desert RATS Test Conductor

"Students are the people who will be carrying on the majority of the vision for space exploration long after folks like me are gone. The more they see of what we are doing and the more we talk to them, the more real space exploration is to them, and the more likely they'll be inspired to work hard and get ready for the future.
Dean Eppler

Mark III Space Suit Test Subject

General comments received from educators indicate that the programming is well received by the students:

"It was better than a personal visit to our school by the scientists since they inserted video clips and we could see where they worked. As an educator, it showed me how valuable technology can be to the learning process when used appropriately and professionally. I was impressed by the session."

"The students were really excited and motivated to participate. It was a very valuable experience. Overall, it was very well done. The speakers were terrific."

"Awesome!! Loads of incredible information and a heartfelt thanks to those who stopped their work to touch base with us and visit with our students."

\section{FUTURE PLANS}

The Digital Learning Networks is committed to continuing this education collaboration with the Desert RATS technical team. The 2007 programs are currently being planned. For more information on the Desert RATS events, as well as other Digital Learning Network programs visit the website at: http://nasadln.nmsu.edu/dln/.

\section{ACKNOWLEDGMENTS}

The authors thank the Digital Learning Network and the Desert RATS teams for all of their support for these programs.

\section{CONTACT INFORMATION}

Heather L. Paul is a Mechanical Engineer with the Advanced Extravehicular Activity Team at the NASA Johnson Space Center. She is the Ventilation Subsystem Manager for the development of the next generation Portable Life Support Systems that will be used with the Lunar and Martian space suits. She also works with the Thermal Subsystem on evaluating cooling garment concepts. Ms. Paul is also the Education and Public Outreach Lead for her team. She can be reached at heather.I.paul@nasa.gov.

Erika R. Guillory is the Special Events Coordinator for The NASA Digital Learning Network. She serves as an Education Specialist and Broadcast Producer for the Johnson Space Center Hub. She has developed and hosted educational programs for the team for approximately 8 years. Ms. Guillory can be reached at erika.guillory-1@nasa.gov. 
